\title{
Perception of Pre-service Teachers at China Rural Area Normal College in Teaching Career Choice
}

\author{
Shen Gju Zou ${ }^{1, a^{*}}$ \\ ${ }^{1}$ Qujing Normal University, Yunnan Province, China \\ 'roscoeshen@163.com \\ * Corresponding Author
}

Keywords: Pre-service Teachers; Sex Difference; Teaching Career Choice

\begin{abstract}
This article explores young people's perspectives on males and females as teachers, contrasting these with teachers' perceptions. It builds on 425 interviews of pre-service teachers. The findings of the study reveal that male and female student teachers have similar motives in selecting teaching as a career. Generally, both groups emphasize altruistic and extrinsic factors. This paper discusses the findings in relation to wider issues concerning gender, and draws conclusions which may be helpful to policy-makers and institutions in the recruitment of students into pre-service teacher training.
\end{abstract}

\section{Introduction}

Lack of male teachers is a current theme in educational discussion. Problems of recruitment, attrition and retirement of those in service make for persistent teacher shortage in many developed and developing countries. The teacher's role in determining the quality, effectiveness and relevance of education has been recognized as a crucial prerequisite to achieving poverty eradication, sustainable human development and equity. While the education system of any country must ensure that enough teachers enter the teaching profession, it must also strive to attract the most capable and appropriate people into the profession. At the same time, it is just as important to ensure that there is a healthy gender balance in the teaching profession. This paper aims to support these initiatives by investigating the reasons why male teachers choose teaching as a career. It is important to take cognizance of what motivates young job-seekers to enter the teaching profession and what makes them stay or leave: this understanding is crucial to any effort at maintaining a stable teaching force, especially in the highly competitive job market of developing economies.

\section{Literature Review}

Female numerical dominance of teaching has been regarded as a problem in various countries in the nineteenth century, as well as today (see, for example, [1]; [2]; [3]). Arguing for the need for more male teachers in schools is often united with concern about boys' problems in schools [4] or with boys' need of male models [5]. This discussion has also been linked to the worries about boys' under achievement, which is not a new discussion either, but raised, for example, by the philosopher John Locke already in the late seventeenth century [6]. Among teachers, the need for more men in the profession is often taken for granted, although many of them address this discussion critically. Often it is stated that boys, but also girls, need male teachers as models. Besides, men are needed at schools, it is argued, because certain male characteristics are needed. Sometimes male as well as female teachers argue for the need for male teachers to raise the status of the profession or to improve the atmosphere in staff rooms[7]. Students' opinions have not been sought as often. 


\section{Purpose of study}

The purpose of the present study is to examine the factors influencing first year undergraduates' choice of teaching as a career. The study is designed expressly to compare the perspectives of male and female student teachers in training.

\section{Method}

The target sample for this study was a cohort of 425 first year undergraduates at a rural normal college who had just started their pre-service teacher training program. Of these student teachers, 70.4\% (n $=299)$ were science and mathematics students, $17.6 \%$ were special needs students $(n=75), 6.1 \%$ were sports and recreational students $(n=26)$ and $5.9 \%$ were students $(n=25)$. Their ages ranged from $20-35$ with a mean of $21.71 .8 \%(n=305)$ were female and $28.2 \%(n=120)$ were male. The study focused on a sample of undergraduates in one university, as it was felt that this would help ensure a good response rate using a questionnaire, but it is recognized that by doing so, any generalizations to the wider population of undergraduates must be made with caution. The survey instrument was distributed to all first year students in the four programs, with $89.9 \%$ return rate. The questionnaires were administered at the beginning of the course when the respondents had not yet established any relationship with the researcher. The returned questionnaires were coded by a research assistant as an ethical safeguard, since the researcher was responsible for the design, teaching and assessment of some subjects in the Bachelor of Education program in which the respondents were enrolled. The sample comprised student teachers who were willing to return the completed questionnaire. The sample size is appropriate considering the total number, and is deemed to reasonably represent the entire group of first year student teachers. The respondents' profile is given in Table 1.

Table 1 Respondents' Profile

\begin{tabular}{|l|l|l|}
\hline Profile & Number & Percentage \\
\hline Gender & & \\
\hline Male & 120 & 28.2 \\
\hline Female & 305 & 71.8 \\
\hline Total & 425 & 100 \\
\hline
\end{tabular}

\section{Instrumentation and analysis}

The student teachers were asked to complete a questionnaire consisting of 25 statements of motives for choosing teaching as a profession, four questions about their background and three open-ended questions about their expectations. The statements were presented with a five-point scale of agreement ranging from ' 5 ' (strongly agree) to ' 1 ' (strongly disagree). Thus, this study relies to a great extent on student teachers' self-reporting. There may have been a tendency for respondents to be defensive or to produce answers they felt to be appropriate and there is certainly no guarantee that they would have told the truth or accurately described their thoughts. The Hawthorne effect [8] (used to explain how the results of a study are affected when the respondents are particularly delighted to be chosen) is reduced partially, at least as a whole cohort is investigated, thus negating much of the feeling of being 'special'. To avoid the 'halo effect', which is the potential desire to please or impress, the names of respondents were not required on the questionnaires. Factor analysis was carried out to examine the structure underlying the motive items and to reduce the variables to several scales or factors so that the motives of the student teachers may be better understood. The principal-component analysis was conducted with maximum iterations for convergence set at 25. The initial factor solution was rotated under the varix rotation, which converged after 12 iterations. The first five factors that have Eigen values greater than unity were further examined [9]. On the basis of the principal-component analysis results, attempts were made to construct meaningful student teachers' motive scales for further analysis. The simplest method is to assign each item to the factor on which it is loaded most highly. This method was used for the three factors with minor adjustment for two items, which were assigned to the construct that is 
conceptually more meaningful than indicated by the factor loadings. These items are marked with an asterisk in Table 2 below. Three factors were retained as they accounted for $68.4 \%$ of the total variance. The first factor which is statistically the most important, accounting for $31.4 \%$ of the variances, is a factor of extrinsic reasons. All of the items with loadings greater than, or equal to 0.60 concerned students' ideas about salaries, long vacations, job security and fringe benefits of being a teacher. The second in importance is an altruistic factor which accounted for $22.6 \%$ of the variance and included items describing perceptions of innate quality for teaching. The third factor accounted for $13.9 \%$ of the variance and items with high loadings dealt with students' internal beliefs such as: 'I can learn a lot from children, a job that I enjoy', and 'suitable for my potential and ability', and this was called intrinsic. The Cronbach's alphas of these three factors were determined. The alpha value of the scale shows that this scale has strong internal consistency as shown in Table 2.

Table 2 Student teachers' motives with Cronbach's alpha

\begin{tabular}{|l|l|l|l|}
\hline Scale/Construct & Item & Number of Items & Cronbach's Alpha \\
\hline Intrinsic & & 7 & 0.77 \\
\hline Extrinsic & & 11 & 0.84 \\
\hline Altruistic & & 7 & 0. \\
\hline Whole Scale & & 25 & 0.81 \\
\hline
\end{tabular}

\section{Result}

Descriptive statistics were employed to find out the most popular motives of student teachers, by gender, for choosing to become teachers. Table 2 sets out the percentages of responses for positive and negative categories as well as the means and the rank order based on the means scores of the item. As can be seen from the table, the most influential motives (having a mean of 4.00 and above on a five-point scale) for both male and female students are similar. The most influential motives are: 'Contribute to society' (Item 13), 'A service of moral value to society' (Item 14), 'A job that is easily compatible with parenthood' (Item 22), 'A secure job' (Item 11), 'Help government achieve Vision 2020' (Item 26), 'A respected job' (Item 28) and 'Opportunity to further studies' (Item 27). Of this group of seven mainly altruistic and extrinsic motives, four are altruistic motives. The high ranking of teaching with regard to 'Contribute to society' (Rank 1) is corroborated by the trainees' responses to the statement that teaching will help the government achieve Vision 2020 (Rank 5). Both male and female trainees also generally agree with the statement that teaching helps to moulid the young generation $(\mathrm{M}=71.6 \%, \mathrm{~F}=70.2 \%)$. However, while female trainees agree strongly with the statement $(\mathrm{F}=86.6 \%)$ that teaching is a respected job, male trainees' perception of the status of teaching is not particularly high as only $58.3 \%$ agree with the statement. More female students (58.2\% as compared to $37.5 \%$ of male students) agree that teaching is a job that is easily compatible with parenthood. Another important reason ranked third by males and fourth by females is job security. It is interesting that $92.1 \%$ of females consider job security as an important motive as compared to $60 \%$ of males. As for the fifth-ranked motive, only $58.3 \%$ of males compared to $86.6 \%$ of females agree that teaching is a respected job. Both groups (males: $85.2 \%$, females: $80.6 \%$ ) also indicate that opportunity for further studies is one of the main motives for choosing teaching as a career. This indicates that in deciding to become a teacher, males place less emphasis than females on the importance of intrinsic motives such as compatibility with parenthood and job security. The next important group of motives (with means above 3.00 and below 3.99) for male student teachers are: 'Reasonable workload' (Item 12), 'Love of teaching' (Item 19), 'A lot of free time/long vacation' (Item 25), 'I want to become a professional teacher' (Item 31) and 'Match my academic qualification' (Item 10). The female student teachers' main motives for choosing teaching as a career are: 'A lot of free time/long vacation' (Item 25), 'Reasonable workload' (Item 12), 'I want to become a professional teacher' (Item 31), 'Influenced by parents' (Item 1) and 'Match my academic qualification' (Item 10). For both groups, the 13 motives are a mix of the three types of motives, the intrinsic motives being the most dominant. 'Reasonable workload' is rated highly by both groups (Male: 83.7\% ; Female: $87.1 \%$ ) and similar percentages are found for 'Long vacation' $(66.6 \%, 68.2 \%)$. Here, both male and female student teachers seem to have been attracted by the service conditions of the 
teaching profession such as 'Long vacation' and 'Reasonable workload'. Particularly noteworthy is the high ranking of Item 1 'Influenced by parents' by female students but not by male students. It appears that $87 \%$ of females chose the teaching career due to parents' influence as compared to $63 \%$ of males. Also, similar percentages are given to 'I want to become a professional teacher' $(\mathrm{M}=73.3 \%, \mathrm{~F}=75.1)$, and to the altruistic reason that 'Teaching matches my academic qualification' $(\mathrm{M}=73.3, \mathrm{~F}=73.5)$ (Table 5). These results indicate that there is a closer match between the two factors the student teachers regard as fairly important in choosing a career and the extent to which they view these factors as being met by teaching. It may be said that the respondents are expressing congruence between their self-efficacy and their own personal identity. At the same time, they express lower personal efficacy in their confidence in their own abilities and talents in undertaking teaching as a career. Lower percentages are given by both male and female student teachers for the altruistic reason of 'Suitable with my potential and ability' $(\mathrm{M}=56.7 \%, \mathrm{~F}=53.5 \%)$. The motives that have means between 2.99 and 2.00 for both male and female student teachers are: 'Good salary' (Item 30), 'Influenced by a friend' (Item 6) and 'Influenced by a former teacher' (Item 4). This group of four motives is related to external influences. Interestingly, only $31 \%$ of males and $27 \%$ of females agree that teaching offers good salaries, which are relatively low figures by comparison with other factors in this group. Of all the 31 motives presented to the student teachers, the least significant is this one (mean score below 2.00): 'Influenced by husband/ wife' (Item 2). Student teachers seem to enter the teaching profession with clear motives and not as a desperate choice. They also seem to realize that while it is not considered a well-paid job, it requires dedication and effort. T-test analyses were performed to examine the differences in the mean scores of male and female student teachers. The mean scores, standard deviations and the values are shown in Table 6 below. The analyses indicate that there is no significant difference between male and female students with respect to all the three motivating factors $(\mathrm{t}=-.003, \mathrm{p}=<0.05 ; \mathrm{t}=0.11, \mathrm{p}=0.05$; $\mathrm{t}=-3.88, \mathrm{p}<0.05)$. This suggests that both male and female student teachers are attracted to teaching as a profession for the same reasons.

\section{Conclusion}

The present study's findings regarding motivations that have attracted men to pursue a teaching career can be of particular use to the policy makers and employment agencies in many countries such as the US, Canada and Australia where the number of men teaching in schools also continues to decline ([10]; [11]). Findings from this study indicate that men are attracted to teaching as a career because of job security and opportunities for further education but they do not consider teaching as having a high social status. While improvement to salary and working conditions may help to address the negative impressions of teaching as a career, recruitment strategies that emphasize teaching as an intellectually demanding, cognitively stimulating career and as a profession in which men can realize their talents and abilities would likely be a more prominent factor in attracting men to enter the teaching profession. Thus, recruitment efforts should not limit their scope by focusing on teachers' potential to make a social contribution to society and the opportunity to work with children, neglecting other important motivations such as job security and greater professional and career advancement which would make the teaching profession a socially valued occupation and therefore attract more men. Examining factors that motivate young people to pursue a teaching career is considered opportune at a time when many governments and employment agencies around the world face growing teacher shortages and attempt to improve teacher recruitment and supply as well as restructure teachers' work and careers. Although teaching appears to be a socially valued profession, many countries such as Australia, the US and the UK and a number of European and Asian countries are currently experiencing difficulties in attracting and maintaining teachers. Unfortunately, increasing salary gaps between teaching and other professions, and the employment conditions in these countries continue to make teaching a less than attractive career option. This study has found that one of the factors that motivated student teachers to choose teaching as a career is favorable service conditions which include long term security and benefits. This illustrates that security and benefit packages matter, so in order to recruit quality teachers, it is important for government to take the initiative in providing more competitive remuneration packages for teachers. 


\section{Acknowledgements}

The research was carried out in Yunnan Province Social Grant (No:QN2015031).

\section{References}

[1] Apple, M. W. Teachers and Texts. A Political Economy of Class \& Gender Relationships in Education. London: Routledge(1986).

[2] Acker, S. Gendered Education. Sociological Reflections on Women, Teaching and Feminism. Buckingham: Open University Press (1994).

[3] Prentice, A. (1998) Mapping Canadian Women's Teaching Work: Challenging the Stereotypes, in A. MacKinnon, I. Elgqvist-Salzman \& A. Prentice (Eds) Education into the 21st Century. Dangerous Terrain for Women? London:Falmer (1998).

[4] Epstein, D. \& Johnson, R. (1998) Schooling Sexualities. Buckingham: Open University Press (1998).

[5] Gannerud, E. Gender Perspective on Teachers' Work: on the lives and work ofwomen primary school teachers (1999).

[6] Cohen, M. (1998) 'A Habit of Healthy Idleness': boys' underachievement in historical perspective', in D. Epstein, J. Elwood, V. Hey \& J. Maw (Eds) FailingBoys? Issues in Gender and Achievement. Buckingham : Open University Press (1998).

[7] Lahelma, E., Palmu, T. \& Gordon, T. (forthcoming, b) Intersecting PowerRelationships in Teachers' Experiences of Being Sexualised or Harassed byStudents, Sexualities (Special issue on sexualities in school) (2000).

[8] Cohen, L., L. Manion, and K. Morrison. Research methods in education. London: Routledge Falmer (2000).

[9] Kim, J., and C.W. Muller. Factor analysis: Statistical methods and practical issues. New York: Sage Publication (1994).

[10] Martin, A.J. Improving the educational outcomes of boys. Canberra: Report to ACT Department of Education, Youth and Family Service (2002).

[11] Riddell, S., and L. Tett. Gender and teaching: Where have all the men gone? Edinburgh: Dunedin Academic (2006). 